\title{
HUBUNGAN PENGETAHUAN DENGAN PEMERIKSAAN PAYUDARA SENDIRI (SADARI) SEBAGAI DETEKSI DINI KANKER PAYUDARA PADA MAHASISWA DIII KEBIDANAN STIKES MURNI TEGUH
}

\author{
Laurena Ginting \\ Program Studi D3 Kebidanan STIKes Murni Teguh \\ E-mail: Laurenaginting2087@gmail.com
}

\begin{abstract}
Cancer death cases in Indonesia are the highest with 21.5 in every 100,000, 70\% of breast cancer patients come to health facilities with an advanced stage. The introduction of cancer is important because it can reduce new cases of cancer. So that the need to prevent early detection efforts to facilitate recognizing risk factors and symptoms of cancer. This type of research is descriptive analytic with cross sectional design. The population in this study were all 32 D-III Midwifery students from STIKes Murni Teguh. The sample amounted to 100 female students. Sampling is done using total sampling. The study was analyzed by univariate and bivariate tests with chi square statistics. From the results of the bivariate test, the results of the Chi square test with the help of SPSS obtained a value of $P=0.001(P \leq 0.005)$ so that it can be said statistically there is a relationship between knowledge with breast self examination (BSE) as early detection of breast cancer. It is recommended that Pure STIKes students firmly increase their knowledge of breast self-examination (BSE) and routinely carry out breast self-examinations according to the time and steps of the examination. STIKes Murni Teguh provides counseling and information to students to routinely conduct $B S E$.
\end{abstract}

Keywords: Knowledge, Self Breast Examination (BSE), students

\begin{abstract}
Abstrak
Kasus kematian kanker di Indonesia menjadi yang tertinggi dengan angka 21,5 pada setiap $100.000,70 \%$ pasien kanker payudara datang ke fasilitas kesehatan dengan keadaan stadium lanjut. Pengenalan penyakit kanker menjadi penting karena dapat menurunkan kasus baru kanker. Sehingga diperlukannya upaya pencegahan deteksi dini untuk mempermudah mengenali faktor risiko dan gejala kanker. Jenis penelitian ini adalah deskriptif analitik dengan desain cross sectional. Populasi dalam penelitian ini adalah seluruh mahasiswi D-III Kebidanan STIKes Murni Teguh yaitu sebanyak 32 orang. Sampel berjumlah 100 orang mahasiswi. Pengambilan sampel dilakukan dengan menggunakan total sampling. Penelitian dianalisa secara univariat dan bivariat dengan uji statistik chi square. Dari hasil uji bivariat menunjukan Hasil uji Chi square dengan bantuan SPSS diperoleh nilai $\mathrm{P}=0,001(\mathrm{P} \leq 0.005)$ sehingga dapat dikatakan secara statistik terdapat hubungan antara pengetahuan dengan pemeriksaan payudara sendiri (SADARI) sebagai deteksi dini kanker payudara. Disarankan agar mahasiswi STIKes Murni Teguh meningkatkan Pengetahuan tentang pemeriksaan payudara sendiri (SADARI) dan rutin melakukan pemeriksaan payudara sendiri sesuai dengan waktu dan langkah - langkah pemeriksaan. STIKes Murni Teguh memberikan konseling dan informasi kepada mahasiswa untuk rutin melakukan SADARI.

Keywords : Pengetahuan, Pemeriksaan Payudara Sendiri (SADARI), Mahasiswa.
\end{abstract}




\section{PENDAHULUAN}

Penyakit kanker di Indonesia memiliki prevalensi yang cukup tinggi. Menurut data Riskesdas (2013) prevalensi kanker di Indonesia adalah 1,4/100 penduduk atau sekitar 347.000 orang. Diprediksi pada tahun 2030 orang meninggal karena penyakit kanker akan meningkat hingga 13 juta orang per tahun. Penyakit kanker tidak hanya terjadi pada orang dewasa, dari sejak balita kemungkinan akan terpapar oleh kanker (Depkes RI, 2017). Berdasarkan Riskesdas (2018) diketahui bahwa prevalensi kanker di Indonesia meningkat dari 1,4\% di tahun 2013 menjadi 1,8\% di tahun 2018.

Kasus kematian kanker di Indonesia menjadi yang tertinggi dengan angka 21,5 pada setiap $100.000,70 \%$ pasien kanker payudara datang ke fasilitas kesehatan dengan keadaan stadium lanjut. Pada tahun 2012 jumlah penderita kanker payudara termasuk tertinggi di dunia dengan persentase 43,1\% (Kemenkes RI, 2016).

Jumlah penderita kanker payudara tidak hanya terjadi pada perempuan usia lanjut dan saat ini kanker payudara mulai terjadi pada perempuan muda bahkan remaja. Deteksi dini kanker payudara sangat penting dilakukan oleh remaja sedini mungkin (Kumparan, 2018).

Penyakit kanker merupakan salah satu penyebab kematian utama di seluruh dunia. Kanker adalah pertumbuhan yang tidak normal dari sel-sel jaringan tubuh yang berubah menjadi jaringan yang ganas dan dapat tumbuh lebih lanjut serta menyebar ke bagian tubuh lainnya sehingga dapat mengakibatkan kematian. Sel kanker tidak matisetelah usianya cukup melainkan akan terus tumbuh dan invasif sehingga sel normal akan terdesak dan mati (Kemenkes RI, 2016).

Saat ini salah satu penyakit kanker yang menakutkan di seluruh dunia dan juga Indonesia adalah kanker payudara. Kanker payudara adalah tumor ganas yang terbentuk dari sel-sel payudara yang tumbuh dan berkembang tanpa terkendali sehingga dapat menyebar di antara jaringan dan organ di dekat payudara atau ke bagian tubuh lainnya.

Pengenalan penyakit kanker menjadi penting karena dapat menurunkan kasus baru kanker. Sehingga diperlukannya upaya pencegahan deteksi dini untuk mempermudah mengenali faktor risiko dan gejala kanker. Diagnosis kanker merupakan penyakit yang sangat menakutkan bagi pasien sehingga diperlukan deteksi secara dini.

Program deteksi dini kanker payudara yang diselenggarakan di 717 Puskesmas dari 9.422 Puskesmas di 32 Provinsi masih menunjukkan persentase yang sangat rendah yaitu sekitar 7,6\%. Rendahnya tindakan pencegahan dan deteksi dini yang dilakukan penyedia pelayanan kesehatan sehingga sangat penting untuk dilakukan tindakan deteksi dini secara sederhana pada wanita mengingat tingginya prevalensi kanker di Indonesia yaitu sebesar $1.4 \%$. Deteksi Dini ini bertujuan untuk menemukan kasus kanker pada stadium dini sehingga dapat dilakukan pengobatan yang cepat dan tepat dan memberikan kesembuhan dan harapan hidup yang lebih lama. (Kemenkes, 2015).

Pencegahan kanker payudara dilakukan melalui deteksi dini dengan cara pemeriksaan payudara sendiri (SADARI) yang bertujuan untuk menemukan kanker payudara stadium awal. SADARI dilakukan pada hari ke tujuh sampai ke sepuluh dihitung menstruasi. Hal ini dilakukan karena pada masa tersebut terjadi penurunan estrogen dan progesteron sehingga kelenjar payudara pada saat itu tidak membengkak dan memudahkan dilakukannya perabaan untuk menemukan kelainan pada payudara (Briliana, 2017).

Pengetahuan merupakan proses yang terjadi setelah manusia melakukan pengindraan terhadap suatu objek melalui pengindraan yang dimiliki oleh manusia, pengindraan dapat dilakukan melalui mata dan telinga (Notoadmojo, 2011). 
Berdasarkan penelitian Sari (2017) diketahui bahwa ada hubungan tingkat pengetahuan Remaja Putri dengan Sikap melakukan Sadari. Dari Hasil Penelitian Adelia (2017) didapat ada hubungan antara pengetahuan prilaku SADARI pada Mahasiswi DIII Farmasi Angkatan 2017 STIKes Nani Hasanuddin Makasar.

Dari studi pendahuluan yang dilakukan oleh peneliti dengan melakukan wawancara pada 6 orang mahasiswa D-III Kebidana STIKes Murni Teguh didapat hanya 2 orang yang melakukan Pemeriksaan Payudara Sendiri (SADARI) dan 4 orang tidak pernah melakukan SADARI.

\section{METODE PENELITIAN}

Penelitian yang dilakukan merupakan penelitian deskriptif dengan menggunakan pendekatan crosssectional. Populasi dalam penelitian ini seluruh mahasiswa D-III Kebidanan Stikes Murni Teguh yang berjumlah 32 Orang dengan tekhnik total sampling, seluruh mahasiswa DIII Kebidanan dijadikan sampel penelitian.

Data dikumpulkan dengan menggunaka kuesioner yang berisi pertanyaan mengenai Hubungan pengetahuan dengan Pemeriksaan Payudara Sendiri (SADARI) sebagai deteksi dini kanker payudara. Analisis data menggunakan analisis univariat, bivariat dengan uji chisquare.

\section{HASIL PENELITIAN}

Tabel 1.

Distribusi Frekuensi dan Presentase

Berdasarkan Umur

No $\begin{gathered}\text { Umur } \\ \text { (Tahun) }\end{gathered} \quad$ F $\quad P(\%)$

\begin{tabular}{cccc}
\hline 1 & $17-20$ & 20 & 62.5 \\
\hline 2 & $21-25$ & 12 & 37.5 \\
\hline & Dari tabel & 1 & menunjukkan bahwa
\end{tabular}

mayoritas responden berusia 17-20 tahun berjumlah 20 orang, $62.5 \%$.
Tabel 2.

Distribusi Frekuensi dan Presentase Pengetahuan Responden tentang Pemeriksaan Payudara Sendiri (SADARI).

\begin{tabular}{cclc}
\hline No & Kategori & F & P(\%) \\
\hline 1 & Baik & 17 & 53.1 \\
\hline 2 & Cukup & 9 & 28.1 \\
\hline 3 & Kurang & 6 & 18.8 \\
\hline
\end{tabular}

Dari tabel 2 menunjukkan mayoritas responden berpengetahuan cukup 17 orang, $53.1 \%$.

Tabel 3.

Distribusi Frekuensei dan Presentase Pemeriksaan Payudara Sendiri (SADARI).

\begin{tabular}{cccc}
\hline No & Kategori & F & P(\%) \\
\hline 1 & Melakukan & 21 & 65.6 \\
\hline 2 & Tidak Melakukan & 11 & 34.4 \\
\hline
\end{tabular}

Dari tabel 3 dapat dilihat bahwa Distribusi Frekuensei dan Presentase Pemeriksaan Payudara Sendiri (SADARI) mayoritas Responden melakukan Pemeriksaan Payudara Sendiri (SADARI) berjumlah 21 orang, $65,6 \%$.

Tabel 4.

Tabel Hubungan Pengetahuan dengan Pemeriksaan Payudara Sendiri (SADARI).

\begin{tabular}{|c|c|c|c|c|c|}
\hline \multirow{2}{*}{\multicolumn{2}{|c|}{$\begin{array}{l}\text { N Pengeta } \\
\text { o huan }\end{array}$}} & \multicolumn{2}{|c|}{$\begin{array}{c}\text { Pemeriksaan } \\
\text { Payudara } \\
\text { Sendiri } \\
\text { (SADRI) }\end{array}$} & \multirow[t]{2}{*}{$\begin{array}{l}\text { To } \\
\text { tal }\end{array}$} & \multirow[t]{2}{*}{$\mathbf{P}$} \\
\hline & & $\begin{array}{l}\text { Mela } \\
\text { kuka } \\
\mathrm{n}\end{array}$ & $\begin{array}{l}\text { Tidak } \\
\text { Melak } \\
\text { ukan } \\
\end{array}$ & & \\
\hline 1 & Baik & 14 & 3 & 17 & \multirow[t]{4}{*}{0.001} \\
\hline \multirow{3}{*}{$\begin{array}{l}2 \\
3\end{array}$} & \multirow{3}{*}{$\begin{array}{l}\text { Cukup } \\
\text { Kurang } \\
\text { Total }\end{array}$} & 7 & 2 & 9 & \\
\hline & & 0 & 6 & 6 & \\
\hline & & 21 & 11 & 32 & \\
\hline
\end{tabular}

Dari tabel. 5 dapat dilihat bahwac Hubungan Pengetahuan dengan Pemeriksaan Payudara Sendiri (SADARI) menunjukkan mayoritas berpengetahuan baik 
dengan jumlah 17 orang, 14 orang melakukan dan 3 orang tidak melakukan pemeriksaan payudara sendiri (SADARI), Hasil uji Chi square dengan bantuan SPSS diperoleh nilai $\mathrm{P}=0,001(\mathrm{P} \leq 0.5)$ sehingga dapat dikatakan secara statistik terdapat hubungan antara pengetahuandengan pemeriksaan payudara sendiri (SADARI).

\section{PEMBAHASAN}

\section{Analisa Univariat}

Dari hasil penelitian didapatkan mayoritas responden berpengetahuan baik dengan jumlah 17 orang, 53.1\%. Pengetahuan merupakan hasil dari berbagai hal yang ditemui oleh pengindraan melalui pengamatan, pengindraan diperoleh melalui panca indra manusia sepert penglihatan, pendengaran, penciuman dan perabaan. Pengetahuan diperoleh melalui 6 tingkatan yaitu Tahu, Memahami, Aplikasi, Analisis, Sintesis dan Evaluasi (Wawan, 2011).

Pengetahuan diperoleh melalui 6 tingkatan yaitu Tahu, Memahami, Aplikasi, Analisis, Sintesis dan Evaluasi (Wawan, 2011)

\section{Analisa Bivariat}

Berdasarkan penelitian didapatkan $17(53,1)$ responden memiliki pengetahuan baik dan yang melakukan pemeriksaan payudara sendiri 21 responden $(65,6 \%)$, berdasarkan hubungan pengetahuan dengan pemeriksaan payudara sendiri didapatkan 17 orang berpengetahuan baik dan 14 orang melakukan pemeriksaan payudara sendiri, 3 orang tidak melakukan pemeriksaan, didapatkan adanya hubungan yang signifikan antara pegetahuan dengan pemeriksaan payudara sendiri, nilai $\mathrm{P}=0,001(\mathrm{P} \leq 0.005)$. Adanya hubungan ini sejalan dengan pengetahuan responden yang baik maka mereka akan melakukan pemeriksaan payudara sendiri, hal ini juga sejalan dengan Wawan (2011) bahwa pengetahuan memiliki 6 tingkat dimana pada tingkat 3 pengetahuan sampai pada aplikasi dengan melakukan halhal yang didapat, didengar dan dilihat, dalam penelitian ini pengetahuan responden pada tingkat aplikasi, yang menunjukkan pengetahuan yang diterima dan didapat responden tentang pemeriksaan payudara sebagai deteksi dini kanker payudara diaplikasikan atau dilakukan dengan responden melakukan SADARI.

Hal tersebut juga didukung dengan penelitian Adelia (2017) adanya hubungan yang signifikan antara pengetahuan dengan sikap mahasiswa dalam melakukan pemeriksaan payudara sendiri didapat dari nilai $p=0.000$. Hal yang sama juga sejalan dengan peneilitian Sinaga (2016) adanya hubungan signifikan antara pengetahuan dengan deteksi dini kanker payudara melalui Pemeriksaan Payudara Sendiri (SADARI) dengan nilai $P$ Value $=0.003(P \leq 0.05)$.

Berbeda dengan penelitian Patandianan (2015) dengan hasil uji statistik $\mathrm{p}=0.438(\mathrm{P} \leq 0,05)$ menyimpulkan bahwa tidak terdapat hubungan antara tingkat pengetahuan responden terhadapan tindakan pemeriksaan payudara sendiri dikarenakan selain pengetahuan ada faktor pendukung lain yang mempengaruhi manusia berprilaku seperti faktor sarana dan prasarana serta faktor lingkungan.

\section{KESIMPULAN}

1. Pengetahuan Responden tentang Pemeriksaan Payudara Sendiri menunjukkan mayoritas responden berpengetahuan cukup 17 orang, 53.1\%.

2. Pemeriksaan Payudara Sendiri (SADARI) mayoritas Responden melakukan Pemeriksaan Payudara Sendiri (SADARI) berjumlah 21 orang, $65,6 \%$.

3. Hubungan Pengetahuan dengan Pemeriksaan Payudara Sendiri (SADARI) menunjukkan mayoritas berpengetahuan baik dengan jumlah 17 orang, 14 orang melakukan dan 3 orang tidak melakukan pemeriksaan payudara sendiri (SADARI), Hasil uji Chi square dengan bantuan SPSS diperoleh nilai $\mathrm{P}$ $=0,001(\mathrm{P} \leq 0.005)$ terdapat hubungan antara pengetahuan dengan pemeriksaan payudara sendiri (SADARI) sebagai deteksi dini kanker payudara di D-III Kebidanan STIKes Murni Teguh. 


\section{SARAN}

1. Bagi Mahasiswa STIKes MurniTeguh meningkatkan pengetahuan tentang pemeriksaan payudara sendiri (SADARI) sebagai deteksi dini kanker payudara dan terus melakukan SADARI secara rutin sesuai dengan tahapan - tahapan dan waktu melakukan sadari.

2. Bagi STIKes Murni Teguh agar memberikan konseling dan terus membagikan informasi kepada mahasiswa untuk rutin melakukan SADARI sertA mengikutsertakan organisasi kemahasiswaan untuk menyebarluaskan informasi tentang SADARI

3. Bagi Peneliti selanjutnya, agar meneliti lebih lanjut dengan menggunakan variabel yang lebih banyak, serta mengembangkan penelitian tentang SADARI sehingga dapat dimanfaatkan di masyarakat.

4. Bagi dinas Kesehatan mengalakan promosi kesehatan tentang SADARI sehingga dapat membantu masyarakat untuk mendeteksi kanker payudara sedini mungkin.

\section{REFERENSI}

Adelia, S. Darwis, Hasanuddin. (2017). Hubungan Pengetahuan dan Sikap Dengan Sadari dalam Upaya Deteksi Dini KankerPayudara Pada Mahasiswi DIII Farmasi Angkatan 2017 STIKes Nani Hasanuddin Makassar. Jurnal Ilmiah Kesehatan Diagnosis Volume 12 Nomor 5 Tahun 2018.

Briliana, A, R, Arafah, Notobroto,H,B.(2017). Faktor yang berhubungan dengan Perilaku Ibu Rumah Tangga MelakukanPemeriksaan Payudara Sendiri. The Indonesian Journal of Public Health Vol 12(2): 143-153.

Departemen Kesehatan RI. (2017). Kementerian Kesehatan AjakMasyarakat Cegah dan Kendalikan Kanker. Artikel Online. Diakses tanggal 08 Januari 2019 dari http://www.depkes.go.id/article/print /17020200002/kementeriancegahdan-kendalikan-kanker.html

Kementerian Kesehatan RI. (2015). Pusat Data dan Informasi Kesehatan Situasi Penyakit Kanker. Diakses tanggal 09 Januari 2018 dari file:///C:/Users/HP/Downloads/ buletin-kanker.pdf

Kementerian Kesehatan RI.(2016). Pusat Data dan Informasi Bulan Peduli Kanker Payudara. Diakses tanggal 08 Januari 2019 daifile://C:/Users/user/download/i nfoDatin\%20bulan\%20peduli\%20ka nker\%20payudara_2016\% 20(1).pdf.

Kumparan.(2018). Kanker Payudara pada Pria, Tanda-Tanda dan Cara Mengeceknya. Diakse tanggal 12 Januari 2019 dari http://kumparan.com/@kumparanstyl e/kanker-payudara-pada-pria-tandatanda-dan-cara-mengeceknya1540529434408966856?ref=bcjuga

Manafe, D.(2018). Prevalensi Penderita Kanker Meningkat. Artikel Online. Diakses tanggal 15 Januari 2019 dari https://www.beritasatu.com/kesehata n/526365/prevalensi-penderitakanker meningkat

Notoadmodjo (2011). Kesehatan

Masyarakat Ilmu dan Seni. Jakarta Rineka Cipta.

Patandiana, Ribka Elda, Suarayasa Ketut, Towidjojo Vera Diana. (2015). Hubungan antara tingkat pengetahuan dan sikap dengan tindakan tentang pemeriksaan payudara sendiri (SADARI) pada wanita usia subur (WUS) di Kelurahan Nunu Kecamatan Tatangga. Medika Taduloko, Jurnal ilmiah Kedokteran, Vol.2 No.2

Sari, N. (2017) Hubungan Tingkat Pengetahuan Remaja Putri dengan Sikap Melakukan Pemeriksaan Payudara Sendiri (SADARI) di SMAN 2 Ngaglik Sleman. Karya Tulis Ilmiah. Diakses tanggal 10 Januari2019daridigilib.unisayogya.ac 
.id/2803/1/Naskah\%20PUBLIKASI

$\% 20 P D F$.

Sinaga, Cristra F, Ardayani, Tri. (2016). Hubungan Pengetahuan dan Sikap Remaja Putri Tentang Deteksi Dini Kanker Payudara melalui Periksa Payudara Sendiri di SMA Pasundan 8 Bandung Tahun 2016. Jurnal Ilmiah Farmasi, 4(1), hal 16-19.

Wawan, A, Dewi M. (2011) Teori Pengindraan dan Pengukuran Pengetahuan, Sikap dan Prilaku Manusia. Yogyakarta Nusa Medika. 